\title{
VIOLÊNCIA ENTRE PARCEIROS ÍNTIMOS, GÊNERO E SAÚDE: A INTEGRALIDADE, A INTERSECCIONALIDADE E A PEDAGOGIA FEMINISTA NO ACOLHIMENTO ÀS MULHERES E NA EDUCAÇÃO EM/NA SAÚDE
}

INTIMATE PARTNER VIOLENCE, GENDER AND HEALTH: INTEGRALITY, INTERSECTIONALITY AND FEMINIST PEDAGOGY IN THE WOMEN'S EMBRACEMENT AND EDUCATION IN HEALTH

Sonia Maria Dantas Berger ${ }^{1}$

\begin{abstract}
RESUMO
A partir de breve demarcação e conceituação do problema da violência contra mulheres, sob as perspectivas de gênero, direitos humanos e saúde pública e, da constatação de sua persistente invisibilidade na assistência em saúde, o artigo aponta algumas consequências para a saúde das mulheres, problematiza o modo como profissionais lidam com tal fenômeno social e, sinaliza limites e demandas abarcados no processo de educação em/na saúde frente ao tema da violência entre parceiros íntimos, apostando-se na potencialidade do diálogo entre os pressupostos feministas e freirianos para o acolhimento das mulheres em situação de violência, orientado pelos princípios da integralidade e da interseccionalidade.
\end{abstract}

Palavras-chave: Violência entre parceiros íntimos; gênero; saúde integral da mulher; Educação na/em Saúde.

\begin{abstract}
From a brief demarcation and conceptualization of the problem of violence against women, under the perspectives of gender, human rights and public health, and the finding of their persistent invisibility in health care, the article points out some consequences for the health of women, problematizes the way in which health professionals deal with such social phenomenon and, it signals limits and demands covered in the process of health education in the face of the theme of intimate partner violence (IPV), focusing on the potential of the

\footnotetext{
${ }^{1}$ Professora Adjunta do Instituto de Saúde Coletiva da Universidade Federal Fluminense (ISC/UFF). Pósdoutora pelo Programa de Pós-Graduação do Instituto de Estudos em Saúde Coletiva da Universidade Federal do Rio de Janeiro (IESC/UFRJ). Psicóloga formada pela Universidade Federal do Rio de Janeiro (UFRJ), com Doutorado e Mestrado em Saúde Pública pela Escola Nacional de Saúde Pública Sérgio Arouca da Fundação Oswaldo Cruz (ENSP-FIOCRUZ) e Especializações em Teorias e Práticas Ambulatoriais em Instituições Públicas (UFRJ e UFF). Na pós-graduação, desenvolve pesquisas nas linhas de investigação em Educação em/na Saúde: saberes e práticas do Programa de Pós-Graduação em Saúde Coletiva e de Atenção Integral a Pessoas em Situação de Violência do Grupo de Estudos em Gerência e Ensino em Saúde (GEGES/ ISC-UFF).
} 


\section{Revista
Debates Insubmissos}

dialogue between feminist and Paulo Freire presuppositions for embracement women's in situation of violence guided by the principles of integrality and intersectionality.

Keywords: Intimate partner violence; gender; Integrality in Health; Education

\section{INTRODUÇÃO}

A Organização Mundial de Saúde reconhece a violência como um problema de saúde pública, definindo-a como "o uso intencional da força física ou do poder, real ou em ameaça, contra si próprio, contra outra pessoa, ou contra um grupo ou uma comunidade, que resulte ou tenha grande possibilidade de resultar em lesão, morte, dano psicológico, deficiência de desenvolvimento ou privação" (KRUG et al, 2002, p.5). A violência dirigida contra mulheres, adolescentes e meninas na família, contra mulheres nas relações de intimidade com companheiros atuais e passados (violência entre parceiros íntimos - VPI) e no mundo público estariam, a priori, enquadradas como tipos de violência interpessoal, sendo ainda classificadas segundo a natureza do ato - físico, psicológico ou sexual - e do vínculo ou relação estabelecida entre perpetrador e vítima da violência.

Porém, embora evidências frente à prevalência e morbidade relacionadas ao fenômeno da violência entre parceiros íntimos apontem para a necessidade de se identificar e tratar dos casos, na avaliação de alguns programas implantados na área da saúde constata-se que poucos médicos e equipes aderem aos programas que procuram incorporar uma atenção diferenciada às pessoas e famílias em situação de violência, conforme tem sido recomendado por organismos e tratados internacionais (RAMSAY et al, 2005; WHO, 2013).

A partir de uma breve demarcação e conceituação do problema da violência contra mulheres, buscamos apresentar as principais consequências para a saúde das mulheres e problematizar o modo como profissionais e serviços de saúde lidam com tal fenômeno social, para que demandas envolvidas na formação inicial/educação profissional e práticas interdisciplinares em saúde sejam sinalizadas e discutidas. 


\section{VIOLÊNCIAS: INTERFACES NO CAMPO DA SAÚDE PÚBLICA E DOS DIREITOS HUMANOS}

Nos contextos nacional e internacional, a violência, enquanto fenômeno social tem sido um dos problemas de saúde pública de maior expressão em todo mundo, ganhando visibilidade tanto em recomendações e estudos veiculados por organismos internacionais como a Organização Mundial de Saúde (OMS), conforme demonstrado no Relatório Mundial sobre Violência e Saúde (KRUG et al., 2002), como nas políticas públicas e normas técnicas brasileiras (BRASIL, 2002; 2011; 2012)

De acordo com o Atlas da Violência (IPEA \& FBSP, 2018), o total de homicídios no Brasil em 2016 "alcançou a marca histórica de 62.517 homicídios, segundo informações do Ministério da Saúde (MS)", o que corresponderia "a uma taxa de 30,3 mortes para cada 100 mil habitantes, que corresponde a 30 vezes a taxa da Europa" (p.3). Os números, quando analisados sob a perspectiva das desigualdades sociais expressas nas relações de raça/cor e gênero, denunciam o genocídio e criminalização dos jovens negros e, o feminicídio como marcos de uma sociedade extremamente racista e machista:

\footnotetext{
Os negros, especialmente os homens jovens negros, são o perfil mais frequente do homicídio no Brasil, sendo muito mais vulneráveis à violência do que os jovens não negros. Por sua vez, os negros são também as principais vítimas da ação letal das polícias e o perfil predominante da população prisional do Brasil. (p.41) [...]

Em 2016, 4.645 mulheres foram assassinadas no país, o que representa uma taxa de 4,5 homicídios para cada 100 mil brasileiras. Em dez anos, observa-se um aumento de $6,4 \%$. (p.44)

[...]

[...] considerando-se os dados de 2016, a taxa de homicídios é maior entre as mulheres negras $(5,3)$ que entre as não negras $(3,1)$ - a diferença é de $71 \%$. Em relação aos dez anos da série, a taxa de homicídios para cada 100 mil mulheres negras aumentou $15,4 \%$, enquanto que entre as não negras houve queda de $8 \%$. (p.51)
}

Constatamos que grande parte dos atos de violência é praticada no âmbito doméstico e das relações íntimas, o que implica, muitas vezes, na subnotificação dos casos, especialmente da violência envolvendo grupos vulneráveis com relação à condições de gênero e ciclos de vida, como as crianças, mulheres e idosos. Estas agressões vividas na privacidade do lar, tidas como a 'parte invisível da violência' (SCHRAIBER et al, 2006, p. 114), apesar 
de nem sempre resultarem em mortes ou lesões graves, trazem enormes danos físicos, psicológicos e sociais às pessoas envolvidas, intensificados ainda por sua ocorrência de forma crônica.

Por isso, consideramos importante resgatar o modo como o fenômeno da violência contra mulheres no âmbito das relações de intimidade tem sido abordado pelos movimentos sociais, em especial pelo movimento de mulheres, pioneiro no trabalho em prol da visibilidade da problemática da violência contra mulheres. Para além de uma descrição sobre diferenças entre identidades masculinas e femininas, o feminismo apontou para o fato das relações sociais de sexo envolverem poder e produzirem injustiça social, demonstrando que o que é da ordem privada e sagrada da família é operado no social (SAFFIOTI, 2001)

Sob o lema de que 'o pessoal é político', como no caso da violência entre parceiros íntimos, alguns marcos conceituais importantes foram sendo construídos neste processo histórico, atravessando desde uma perspectiva inicial mais 'denuncista' (quem ama não mata) e 'vitimista', que reconheceu na mulher apenas o lado passivo da situação/relação, até as concepções mais contemporâneas que apostam na possibilidade de um papel mais ativo da mulher, que passa a ser considerada como uma pessoa em situação de violência e a contar com redes de apoio e políticas públicas para a superação da violência (GREGORI, 1993; SCHRAIBER et al, 2005; BRASIL, 2011).

Como consequência deste processo, os temas dos direitos das mulheres e da violência de gênero passaram a ser abordados em diferentes conferências, tratados e convenções internacionais. Especialmente nas últimas três décadas, por conta da evolução de noções como direitos humanos e desenvolvimento sustentável, a promoção da igualdade e equidade entre os sexos para alcançarmos a justiça social é ratificada.

Na Conferência de Direitos Humanos de Viena, em 1993, foi adotada pela primeira vez, uma definição oficial das Nações Unidas para a violência contra a mulher, que incluiria, conforme apontado por Heise et al: "Todo ato de violência de gênero que resulte em, ou possa resultar em dano ou sofrimento físico, sexual ou psicológico da mulher, incluindo a ameaça de tais atos, a coerção ou a privação arbitrária da liberdade, tanto na vida pública como na vida privada" (Economic and Social Council, 1992, apud HEISE et al, 1994, p.3). 


\section{Revista
Debates Insubmissos}

Nesta perspectiva, a violência contra a mulher, portanto, inclui a violência doméstica ou 'intrafamiliar', praticada por marido ou companheiro; a violência sexual praticada por parentes (inclusive maridos, ex-maridos e namorados) e por desconhecidos; o assédio sexual e moral nas relações de trabalho, no sistema de ensino e na relação médico-paciente, entre outras.

Fundamentalmente, a importância que diferencia a Conferência de Viena das demais, deve ser reconsiderada por garantir a indivisibilidade e a universalidade dos direitos humanos:

Em Viena, supera-se a dicotomia entre Direitos Civis e Direitos Políticos e Direitos Econômicos, Sociais e Culturais, adotando-se a premissa de indivisibilidade e universalidade dos direitos humanos. E, pela primeira vez, reconhece-se que as ameaças à vida e o tratamento cruel e desumano que ocorrem na esfera privada, inclusive o estupro, devem ser considerados abusos contra os direitos humanos (CORREA, 2001, p.6).

Vale comentarmos que, na definição de violência contra a mulher como "ato de violência de gênero', não encontramos, inicialmente, nenhuma consideração sobre o que seria abordado como 'violência de gênero'. Se a considerarmos, então, como um fenômeno que acontece por motivo de construção socialmente desigual para homens e mulheres, em função de seu sexo, estaria sugerida a possibilidade de que o homem também sofra as consequências da violência baseada em gênero.

De fato, constatamos o peso diferencial de gênero quando se demonstra estatisticamente o quanto os homens sofrem mais os efeitos da violência no âmbito público homicídios e acidentes, por exemplo - do que as mulheres (estas, por sua vez, mais atingidas no âmbito privado de suas vidas). Ter que ser 'forte', 'destemido' e 'não levar desaforo para casa' traz sim consequências para muitos homens. Em uma visão relacional dos gêneros, não podemos ignorar nem o fato das violências que atingem homens na esfera pública também serem relacionadas aos papéis e estereótipos de gênero, embora não praticadas por mulheres, nem as possíveis consequências destas violências públicas para as relações íntimas entre os gêneros (DANTAS-BERGER \& GIFFIN, 2005)

Tais interfaces têm sido exploradas nos estudos de gênero sobre as masculinidades, os quais são de extrema importância, especialmente na abordagem da violência entre parceiros 
íntimos, ressaltando-se tanto os aspectos relacionais como os estruturais implicados na complexidade de tal fenômeno social (NOLASCO,1995; INSTITUTO PAPAI, 2003; LIMA, BÜCHELE \& CLIMACO 2008). Sabemos que as dificuldades crescentes em garantir a sobrevivência familiar através de um ganho digno e estável, base da tradicional identidade masculina de 'provedor', por exemplo, tem estreita relação com a atitude masculina perante uma gravidez podendo estar relacionada com o início da violência doméstica justamente durante a gravidez (DANTAS-BERGER \& GIFFIN, 2011).

No panorama brasileiro das políticas públicas para mulheres (BRASIL, 2008; BRASIL, 2016), que inclui marco legal para enfrentamento do problema da violência contra mulheres, através de legislação específica - Lei Maria da Penha (BRASIL, 2006), encontramos como referência, a definição de violência contra mulheres da Convenção Interamericana para Prevenir, Punir e Erradicar a Violência Contra a Mulher - Convenção de Belém do Pará de 1994, que é muito similar àquela proposta em Viena. No caso da lei brasileira, são introduzidas ainda especificidades relativas aos danos morais e patrimoniais decorrentes da violência (como rasgar documentos, quebrar objetos da casa e da mulher, entre outras), conforme vemos nas disposições gerais: "Para efeitos desta Lei, configura violência doméstica e familiar contra a mulher qualquer ação ou omissão baseada no gênero que lhe cause morte, lesão, sofrimento físico, sexual ou psicológico e dano moral ou patrimonial [...]" (Lei n ${ }^{\circ} 11.340 / 2006$, Capítulo I, Artigo 5º

$\mathrm{Na}$ sequência, o artigo $5^{\circ}$ da Lei detalha em que âmbitos serão considerados tais violências - doméstico, familiar e em 'qualquer relação íntima de afeto', atual ou passada, assim como introduz parágrafo único que ratifica que tais situações independem da orientação sexual das pessoas envolvidas, o que consideramos muito relevante para que a diversidade em termos de identidade de gênero e sexualidade sejam consideradas, como no caso das mulheres transgêneros e/ou daquelas que estão em relações homoafetivas, ainda que constatemos resistências baseadas em preconceitos associados à heteronormatividade para que os direitos dessas mulheres e casais sejam garantidos ou interpretados dentro dos marcos jurídicos previstos na lei. 
De qualquer forma, para finalizarmos provisoriamente as problematizações quanto à complexidade conceitual do tema, o que parece ser considerado comum na articulação entre violência e gênero em muitos dos estudos realizados e que reforça a opção dos pesquisadores pela ênfase na violência praticada por homens contra mulheres, é, justamente, em função de ser "alta sua incidência e severidade quando comparada com a violência praticada por mulheres contra homens" (SUÁREZ E BANDEIRA, 1999, p.24).

Neste sentido, temos a outra face do problema: os efeitos da violência perpetrada por homens contra mulheres associam-se à diferentes situações de morbidade e causas de mortalidade feminina, e, portanto, dada sua alta prevalência enquanto fenômeno de agravo e ameaça à vida e à qualidade da existência, faz parte do universo da saúde pública (MINAYO \& SOUZA, 1999).

Como vimos, a OMS reconhece a violência como um problema de saúde pública. A violência entre parceiros íntimos, enquanto violência interpessoal pode ser entendida como: "qualquer comportamento dentro de um relacionamento íntimo que causa dano sexual, psicológico ou físico para os envolvidos na relação" (KRUG et al., 2002, p. 91).

Sendo assim, retomamos a reflexão sobre o problema, apostando na interseção entre a saúde pública e os direitos humanos aplicados à proteção das mulheres contra possíveis negligências com relação às suas necessidades em saúde, quando buscam os serviços com suas queixas e sofrimentos invisíveis decorrentes das situações de violência doméstica.

\section{A MAGNITUDE DO PROBLEMA DA VIOLÊNCIA ENTRE PARCEIROS ÍNTIMOS E SEUS EFEITOS NA SAÚDE DAS MULHERES}

Tanto no estudo pioneiro de Heise e colaboradores (1994) como em outros reunidos em relatórios da OMS, a alta incidência de violência de homens contra mulheres é demonstrada, sendo a forma mais endêmica encontrada nos estudos a violência sexual e física de companheiros íntimos contra suas mulheres “[...] em muitos países, entre um quarto e mais da metade das mulheres informaram ter sido violentadas fisicamente por um parceiro atual ou passado" (HEISE et al., 1994, p.5-6). Nessa mesma perspectiva Who assevera que "Em todo 


\section{Revista
Debates Insubmissos}

o mundo, $30 \%$ de todas as mulheres que estão em um relacionamento sofreram violência física e/ou sexual pelo parceiro íntimo" (WHO, 2013, p.32)

Ao levantarmos a ocorrência da violência entre parceiros íntimos ao longo da vida das mulheres, as estimativas brasileiras chegam a ser superiores em determinadas regiões do país, (REICHENHEIM et al, 2011). Na investigação multicêntrica capitaneada pela Organização Mundial de Saúde, pesquisadoras brasileiras constataram que na cidade de São Paulo, entre mulheres que tiveram companheiro pelo menos uma vez na vida, a taxa de prevalência da violência física por parceiro íntimo, tal como tapa, empurrão, soco, chute, estrangulamento, queimadura ou ameaça com arma branca ou de fogo foi de $27 \%$ enquanto na Zona da Mata (PE) chegou a 34\% (SCHRAIBER \& D'OLIVEIRA, 2002).

No campo da violência sexual doméstica, a associação entre lares violentos e estupro conjugal ainda é pouco reconhecida e/ou detectada pelos serviços brasileiros em geral. Na área de investigações de base populacional, a pesquisa domiciliar e nacional "A mulher brasileira nos espaços público e privado" (VENTURINI, RECAMÁN \& OLIVEIRA, 2004) é considerada pioneira para tais dados. Nesta pesquisa, uma amostra de 2.502 mulheres com 15 anos de idade, ou mais, distribuídas em 187 municípios de 24 estados das cinco macrorregiões do país foi entrevistada. Foi utilizado questionário estruturado, no qual além da violência e de outros assuntos relacionados à saúde reprodutiva e sexualidade, foram abordados temas como a divisão sexual do trabalho e a participação da mulher em espaços públicos e privados. Cerca de uma em cada cinco das entrevistadas declarou espontaneamente ter sofrido algum tipo de violência por parte de algum homem. Quando estimuladas pelas entrevistadoras, através da citação de diferentes formas de agressão, $24 \%$ declaram ter sofrido ameaças com armas ao direito de ir e vir, 22\% declaram agressões físicas sofridas diretamente e $13 \%$ de estupro conjugal ou abuso.

Em 2010, a pesquisa foi novamente realizada, desta vez por meio de parceria entre a Perseu Abramo e o SESC com objetivo de atualizar os dados, porém incluindo o público masculino entre os entrevistados (VENTURINI \& GODINHO, 2013). Assim, foram entrevistadas 2.365 mulheres e 1.181 homens, com 15 anos de idade ou mais, nas 25 unidades da federação, cobrindo áreas urbana e rural. Na comparação, se no ano de 2001 os resultados 


\section{rearata 6 \\ Debates Insubmissos}

indicaram que a cada 15 segundos, uma mulher era espancada, no ano de 2010, a cada 24 segundos, uma mulher seria vítima de espancamento no Brasil, número ainda muito elevado.

Diante de tal magnitude, as consequências em termos dos efeitos imediatos e crônicos na saúde das pessoas que vivem e convivem com tais situações de violência precisam ser nomeadas e visibilizadas para que a linha de cuidado em saúde possa ser implementada, a qual pressupõe o acolhimento, o atendimento, a notificação e o encaminhamento dos casos (BRASIL, 2010).

O Ministério da Saúde, buscando dar visibilidade à violência de modo a viabilizar o registro de sua magnitude, tipologia, gravidade, perfil das pessoas envolvidas, localização de ocorrência e outras características dos eventos, desenvolveu o Sistema de Vigilância de Violências e Acidentes. Desde 2011, a notificação de violências passou a ser compulsória para todos os serviços de saúde públicos e privados, as quais fazem parte do Sistema Nacional de Agravos de Notificação Compulsória (SINAN). Entre os dados dos atendimentos por violência doméstica, sexual e/ou outras violências registrados no SINAN, em 2014 e analisados no Mapa da Violência (WAISELFISZ, 2015), registra-se que:

[...] foram atendidas 223.796 vítimas de diversos tipos de violência. Duas em cada três dessas vítimas de violência (147.691) foram mulheres que precisaram de atenção médica por violências domésticas, sexuais e/ou outras. Isto é: a cada dia de 2014, 405 mulheres demandaram atendimento em uma unidade de saúde, por alguma violência sofrida. (p.42)

$[\ldots]$

Para as jovens e as adultas, de 18 a 59 anos de idade, o agressor principal é o parceiro ou ex-parceiro, concentrando a metade do todos os casos registrados. (p.48)

De modo geral, portanto, este quadro de prevalência da violência na vida das mulheres pode resultar, entre outros agravos, tanto em consequências não fatais para a saúde física como as IST's, as lesões, a doença pélvica inflamatória, bem como sofrimento psíquico, expresso em transtornos como ansiedade, depressão, desordens alimentares. Os casos de suicídios e homicídios são efeitos considerados fatais (HEISE et al, 1994):

De fato, no estudo Multipaíses já citado, verificamos que as mulheres que sofreram violência relataram de 2 a 3 vezes mais a intenção e a tentativa de suicídio do que aquelas que não sofreram, além de mais problemas relacionados ao uso diário de álcool e à bebida nos últimos 12 meses. Em subprojeto do mesmo estudo, no que se refere aos transtornos mentais 
comuns como a depressão e ansiedade foi encontrada prevalência de 49,0\% entre mulheres que relataram algum tipo de violência e de 19,6\% entre as que não relataram (LUDERMIR et al., 2008).

Na literatura médica, o Transtorno de Estresse Pós Traumático (TEPT) é reconhecido como um dos agravos recorrentes e responsável pela má qualidade de vida das pessoas que sofreram algum tipo de violência, sendo cada vez mais elucidada sua relação com diversas situações de abuso e violência sexual prévias na vida das mulheres. O fato é que esse transtorno não deveria ser de interesse somente da área psiquiátrica, mas sim de toda a classe médica e de outros profissionais da saúde, o que ratificaria o reconhecimento de que a violência é um problema de saúde, já que pode ser o fator desencadeante para diversas outras patologias. Porém, muitas vezes, tal problemática social não é levada em consideração e nem abordada nas anamneses.

Especificamente no que relaciona aos impactos da violência doméstica e de parceiros íntimos (VPI) sobre a saúde sexual e reprodutiva das mulheres, não há como negarmos que muitas vezes o abuso está relacionado a problemas de grande magnitude e complexidade como a gravidez indesejada, a infecção pelo HIV e outras DSTs, bem como complicações da gravidez, tomando caminhos variados até seu desfecho, incluindo o abortamento clandestino em condições inseguras. Por outro lado, a associação entre a ocorrência da violência entre parceiros íntimos (VPI) no ciclo gravídico-puerperal ampliado e a morbidade e mortalidade materno infantil, ainda é uma questão pouco explorada, apesar das pesquisas nos serviços de saúde cada vez mais apontarem tal relação.

Estudos de revisão, ao compararem diferentes desfechos entre as mulheres que sofreram VPI no período da gestação com aquelas que sofreram violência fora deste período, identificam que pode ser três vezes maior o risco das primeiras sofrerem alguma tentativa de homicídio ou serem mortas. Concluíram que a violência na gestação relaciona-se a um padrão muito grave de violência, sendo um evento que pode ser mais frequente do que vários agravos habitualmente rastreados durante o pré-natal como diabetes e hipertensão arterial. (MCFARLANE ET AL., 2002) 
Destacamos ainda, que a própria gravidez pode ser resultado da VPI, quer seja pela relação sexual forçada, "cedida" ou pela recusa do parceiro ao uso de métodos contraceptivos (DANTAS-BERGER\& GIFFIN, 2005).

Mas, até que ponto estes agravos resultantes das situações de VPI são nomeados, percebidos e identificados nos serviços de saúde? E se são identificados, de que forma são acolhidos e tratados? Estas são algumas questões que veremos a seguir.

\section{SERVIÇOS, PROFISSIONAIS E EQUIPES DE SAÚDE (DA MULHER): PANORAMA DE PRÁtiCaS E DESAFIOS DA EDUCAÇÃo EM/ NA SAÚde FRENTE AO TEMA DA VPI}

Uma das tendências na literatura internacional nos campos da saúde e da violência doméstica tem sido o desenvolvimento de pesquisas e a implantação de programas e protocolos que promovam a identificação dos casos, principalmente entre a população de crianças e mulheres atendidas nos diversos níveis de atenção, para que intervenções específicas e/ou prevenção de novos incidentes seja viabilizada. Os profissionais e serviços de saúde são, assim, considerados estratégicos no enfrentamento da violência entre parceiros íntimos, uma das formas mais comuns de violência contra as mulheres (VELZEBOER et al, 2003; D’OLIVEIRA \& SCHRAIBER, 2017).

Pesquisas concluem que "o que cada mulher em situação de violência traz aos serviços de saúde não é a violência como um problema: em geral traz apenas seus efeitos" (SCHRAIBER et al., 2005:94). A dificuldade das mulheres falarem deste problema é consolidada se os serviços também não abordam a questão. Como ratificado nas considerações abaixo:

\footnotetext{
Mesmo sendo subestimada a magnitude do agravo, devemos considerar em nossas proposições que elas chegam cotidianamente a todos os setores de saúde da rede pública e privada do país, também aí, permanecendo, na maior parte das vezes, invisível os sinais de violência (MENDES, 2005, p.130).
}

Reconhecemos que a atuação do setor saúde na trajetória das mulheres em situação de violência nem sempre contempla serviços ou intervenções que englobem todos os tipos (auto 


\section{novist \\ Debates Insubmissos}

infligida, interpessoal ou coletiva) e natureza das violências (física, sexual, psicológica, negligência, entre outras) vivenciadas pelas mesmas, muitas vezes superpostas.

Sobretudo, ressaltamos a invisibilidade do tema específico e grave da violência entre parceiros íntimos, apesar de ser este o tipo mais recorrente de situação de violência a que mulheres e jovens estão submetidas no cotidiano de suas vidas. Em especial se comparada à atenção prevista para mulheres que vivem a violência sexual por estranho e procuram ajuda. Estas, pelo menos nos locais em que a rede intersetorial de atenção em violência funciona minimamente, após buscarem a delegacia, podem ter a oportunidade de serem informadas sobre ou encaminhadas para um serviço de saúde de referência e atendidas dentro do protocolo previsto pelo Ministério da Saúde (BRASIL, MS, 2012).

Neste caminho, importantes iniciativas intersetoriais somaram-se para fazer valer direitos das 'vítimas' de violência, especialmente o direito a interromper uma gravidez decorrente do estupro (conforme previsto, desde 1940, no Código Penal Brasileiro). Pouco a pouco, uma atenção mais integral em saúde tem sido normatizada, através da qual, além do aborto legal, o acesso à anticoncepção de emergência e à profilaxia para o HIV são algumas rotinas previstas (BRASIL, 2012). Entretanto, vale registrar que uma das grandes preocupações atuais com relação ao atendimento às mulheres vítimas de violência sexual, incluindo-se a gravidez resultante de estupro conjugal, refere-se ao acesso das mesmas aos serviços, especialmente àqueles que de fato oferecem o abortamento previsto em lei e a anticoncepção de emergência, pois apesar de contarmos com a normatização da atenção, é a qualidade deste acolhimento que vem sendo questionada:

\footnotetext{
Sabemos que as práticas de cuidado que ensejam produção de autonomia esbarram a todo momento com práticas tutelares, racistas, machistas e misóginas, que objetificam as mulheres. $\mathrm{O}$ atual Estatuto da Família, em tramitação no Congresso Nacional, as leis que visam impedir o aborto legal, as movimentações sociais que tentam impedir que as escolas efetuem debates acerca de questões de gênero, dentre outras práticas conservadoras que vêm se intensificando em nosso país, esvaziam as práticas de cuidado como dispositivos fundamentais de afirmação da vida (HECKERT, 2017, p.109-110).
}

No que se refere às mulheres em situação de violência doméstica/conjugal, quando encontramos alguma referência relacionada à atenção em saúde que buscaram ou receberam, não avaliamos que tenham sido as mesmas atendidas, dentro de rotinas de atenção sensíveis à 
abordagem da violência entre parceiros íntimos, em seu viés de gênero e de direitos humanos. Sabemos que muitos agravos informados pelas mulheres nas emergências em saúde, na verdade, mascarados como acidentes (como os tombos de escada, escorregões), ou as dores sem nome das poliqueixosas, podem, na realidade, esconder um ato intencional, uma situação de violência. De modo geral, os programas e serviços de saúde não contam ainda com protocolos de atenção para casos de VPI, independentemente da situação referente à notificação compulsória de tais agravos prevista no Sistema de Vigilância de Acidentes e Violências do SUS (BRASIL, 2011a; MENEGUEL \& PORTELA, 2017).

Observamos que a 'invisibilidade' da VPI é normalizada em sociedades que consideram que 'em briga de marido e mulher ninguém mete a colher' e retrata tanto as dificuldades das mulheres envolvidas em falar sobre suas vivências como as dos profissionais em perguntar, sendo assim perpetuada ao longo do tempo.

Assim, os profissionais de saúde seriam, de fato, aliados fundamentais no enfrentamento deste problema. Mas, como se sentem e atuam diante de uma questão social tão complexa como a violência?

Entre outras dificuldades, pesquisas mencionam as seguintes barreiras para que algum acolhimento das pessoas em situação de violência seja realizado: falta de recursos pessoais e institucionais, preconceitos e estereótipos culturais (por ex. concepção da violência doméstica como problema de foro íntimo), medo de represália do agressor, falta de preparação e de espaços de discussão para as equipes (HEISE et al, 1999).

De fato, notamos que, em termos da formação e prática em saúde, apesar dos profissionais, especialmente aqueles alocados nos serviços de saúde sexual e reprodutiva, saúde mental e emergências estarem em posição privilegiada para identificação e acolhimento das mulheres que vivem situação de violência doméstica e sexual, nem sempre tiveram os mesmos a oportunidade de serem devidamente sensibilizados, capacitados e/ou reconhecidos em suas potencialidades para a abordagem de temas sensíveis como aqueles envolvidos neste tipo de atendimento, especialmente no contexto brasileiro. Além dos aspectos clínicos/quantitativos, pouco se tem preparado qualitativamente os mesmos para a abordagem de temas "sensíveis" (como seria o caso da violência contra mulheres) e moralmente 
carregados que incluem a necessidade de lidarem com a atenção a questões sociais complexas, e com suas próprias percepções e sentimentos, entre outros aspectos, que vão além de uma prática e abordagem biomédica (DANTAS-BERGER \& CLARKSON, 2014)

A investigação qualitativa de Soares (2003) nos aponta uma transitoriedade na incorporação dos aspectos conceituais e epistemológicos necessários ao acolhimento das mulheres em situação de violência. Ela partiu do pressuposto inicial da 'resistência' de profissionais das equipes multidisciplinares em saúde em aderir a programas de assistência a mulheres em situação de violência sexual, mas focalizou sua análise no âmbito das 'representações sociais' e não do conhecimento' sobre o tema. Ainda que os resultados apontassem para uma transição entre a "concepção moralista/religiosa à promoção dos direitos e da autonomia das mulheres [...]" a autora considerou que, processual e lentamente as experiências de atendimento através da atenção técnica normatizada aos casos de violência sexual "têm possibilitado mudanças de valores e a ressignificação da prática dos profissionais" (p.399). Em outras palavras, tais experiências colocam em cena, situações e temas relacionados, como abortamento, violência sexual e doméstica, relações de gênero, sexualidade, entre outros, que acabam por dar visibilidade sobre como:

O despreparo para lidar com estas questões esteve relacionado com a falta de capacitação [...] uma vez que este tema [violência sexual e agravos] não faz parte da formação acadêmica dos profissionais de saúde, junto à crença de que esta não é uma problemática pertinente ao setor saúde. (SOARES, 2003, p.400)

Por esta razão, experiências diversas referentes à incorporação da temática da violência na formação das equipes de saúde, recomendam que as propostas metodológicas de educação em/na saúde, para além dos aspectos epidemiológicos que informem sobre a prevalência e os aspectos técnicos de treino para o manejo da situação (o 'como' perguntar e para onde encaminhar, por exemplo), incorporem e promovam a reflexão das vivências e crenças dos participantes, com vistas a uma maior responsabilização dos profissionais de saúde diante do problema e um acolhimento 'implicado' dos casos ( DANTAS-BERGER, 2011).

No plano pedagógico relacionado aos processos de educação em saúde com as usuárias do SUS sobre as violências baseadas em gênero, valeria um resgate histórico das 
experiências das mulheres com os grupos de reflexão, onde as vivências relacionadas ao corpo e à sexualidade, aos conflitos nas relações íntimas e/ou familiares, bem como às dificuldades na inserção no mundo do trabalho eram compartilhadas, problematizadas e, assim, compreendidas enquanto processos sociais amplos que afetavam todas as mulheres, consubstanciando-se em uma proposta educativa e de luta política e coletiva transformadora.

Ratificamos a potencialidade de tal resgate histórico, já que, no plano epistemológico, a contribuição do movimento de mulheres para a elaboração conceitual e política da categoria "gênero", tão imbricada no problema da violência contra mulheres, deu visibilidade à questões até então referenciadas à esfera do natural, do biológico, colocando em cena outro modo de produção de conhecimento que vai do concreto ao abstrato, do corpo para a razão, da experiência para a teoria, questionando assim o paradigma hegemônico da racionalidade dicotômica que separa razão e emoção e afirmando o "conhecimento situado" (Haraway,1995), não neutro, mas engajado.

A epistemologia feminista e o ideário do feminismo foram bases conceituais e políticas que orientaram os princípios do Programa de Atenção Integral à Saúde da Mulher (PAISM) e que nos são ainda tão caros, a todos e todas que somos comprometidos com a promoção dos direitos das mulheres e enfrentamento das violências, especialmente aquelas baseadas em gênero. Entretanto, em tempos de políticas neoliberais, de mercantilização da vida e de esgarçamento dos coletivos de ação, tais ideários estão cada vez mais ausentes do cotidiano de ensino nas universidades e da assistência prestada no SUS. Segundo Villela e Monteiro (2005), o "foco na família, a fragmentação das ações voltadas para a mulher" (p. 22), assim como os tipos de treinamentos focados no "desempenho técnico" e que priorizam ações de saúde materno-infantil, vêm diluindo os pressupostos do PAISM.

Por fim, vale ratificar ser fundamental a perspectiva da interseccionalidade no acolhimento humanizado em saúde, de modo a se considerar a diversidade das identidades e experiências das mulheres quanto aos diferentes eixos identitários, tais como raça/etnia, classe, sexualidade/orientação sexual, religião, idade/geração, territorialidade (STEVENS et al, 2017). Ou seja: 


\section{novist

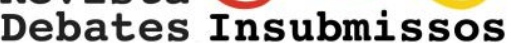

Não é possível efetuar práticas de cuidado que se deem de modo a afirmar a integralidade e a resolutividade das ações de saúde sem que sejam incluídas as questões relativas ao racismo, ao machismo e as desigualdades sociais na produção de saúde. (HECKERT, 2017, p.110)

\section{CONSIDERAÇÕES FINAIS}

[...] É uma coisa que até a gente pode começar a pensar mais... Porque a gente sempre acha que pode ser uma coisa infecciosa. A gente pede [exame de] urina, a gente examina, a gente vê se tem corrimento ou não [...] e acaba que esquece de perguntar essas coisas importantes (profissional da equipe de obstetrícia entrevistada, sobre o que acha de abordar a VPI na consulta - Projeto Violência Doméstica e Gravidez: Qualificando o Acolhimento) $)^{2}$.

“[...] às vezes a pessoa está com problema, [...] com pressão alta, pode não ser que ela que esteja com um problema nela, às vezes ela está nervosa porque aconteceu alguma coisa com ela e, [...] não pode expressar com ninguém [...] o médico vai ser a melhor pessoa, [...] ainda mais no período que é do pré-natal (gestante entrevistada sobre o que acha de falar da VPI na consulta - Projeto Violência Doméstica e Gravidez: Qualificando o Acolhimento) (DANTAS-BERGER et al, 2007).

Como visto, no artigo e nas falas em epígrafe, profissionais de saúde são apontados como estratégicos no enfrentamento da violência entre parceiros íntimos, no sentido de interromper o círculo vicioso do não-acolhimento, que reforça o silêncio em torno do problema. Como a identificação dos casos é o primeiro desafio a vencer, a sensibilização sobre os decorrentes problemas de saúde é apontada como um caminho possível para motivar, inicialmente, a fala de ambas as partes (mulheres e profissionais).

Ao mesmo tempo, sendo um problema social complexo que foge aos limites do modelo biomédico de curar doenças com condutas medicamentosas individuais, é preciso mostrar que os profissionais de saúde têm, mesmo assim, uma contribuição importante a dar, no desencadeamento do que parece exigir um esforço inter e multiprofissional (envolvendo médicos, enfermeiros, psicólogos, assistentes sociais, agentes comunitários, por exemplo) e

\footnotetext{
${ }^{2}$ Projeto de pesquisa-ação, desenvolvido em hospital estadual de referência para gravidez de alto risco no Rio de Janeiro, que teve como objetivo principal "gerar conhecimentos para a elaboração e implantação de um modelo de detecção e acolhimento qualificado de casos de violência doméstica na gravidez"). A execução foi de responsabilidade do Núcleo de Gênero e Saúde - Departamento de Ciências Sociais da Escola Nacional de Saúde Pública Sérgio Arouca/Fiocruz, contando com os seguintes apoios: Projeto de Consultoria, Treinamento e Desenvolvimento de Sistema de Informação e Monitoria para o Programa de Assistência Hospitalar à Gestação de Alto Risco - Instituto Fernandes Figueira/PAISMCA/Secretaria de Estado de Saúde do Rio de Janeiro; Conselho Nacional de Desenvolvimento Científico e Tecnológico - CNPq,
} 
intersetorial, através da articulação de uma rede de serviços (Delegacias, Instituto Médico Legal, Abrigos, Defensoria Pública, Centros de Referência para Mulheres em Situação de Violência, Movimentos Sociais, ONGS, entre outros). O acolhimento, para além de um processo de medicalização, envolve a identificação dos casos, o acompanhamento dos problemas de saúde relacionados, a informação sobre os direitos das mulheres e os recursos psicossociais, jurídicos e de segurança disponíveis para as mulheres que decidem se confrontar com a situação vivida.

Ao contrário do que imaginam muitos profissionais, de que a mulher pode se sentir ofendida ou constrangida em falar sobre seu problema, experiências no campo da pesquisa qualitativa mostram que muitas delas, frequentemente, expressam seu alívio em poder compartir o assunto com um ouvinte solidário, quando abordadas por entrevistadoras e profissionais preparados para acolher suas visões, no espírito de compreensão e aceitação, sem 'julgamento'.

Apreender esta complexidade e respeitar o direito das mulheres de agir - ou não - em qualquer momento (deixar, ficar ou denunciar o parceiro, por exemplo), exige que os profissionais de saúde tenham, igualmente, oportunidade para expressar e compartir suas próprias visões, experiências, dúvidas e considerações perante o problema, também num ambiente de acolhimento, compreensão e informação qualificada (GIFFIN \& DANTASBERGER, 2007; BERGER et al, 2014). Tais estratégias de 'escuta' e acolhimento para mulheres e profissionais (e também para os aspirantes, como alunos da graduação) podem prover insumos cruciais, abrir um caminho efetivo para ouvi-los e iniciar um trabalho com a violência doméstica dentro de um serviço ou programa de saúde, articulado aos demais serviços da rede e recursos comunitários disponíveis.

Ao invés de uma formação tecnicista, como a que temos ainda hoje em nosso país, a formação em saúde demanda projetos político-pedagógicos de educação inicial e permanente em saúde, referidos a outro paradigma de produção de conhecimentos que articule a educação, a saúde e o trabalho e integre os processos de ensino, pesquisa e a assistência numa perspectiva mais crítica e, mais, muito mais participativa, engajada e inovadora pedagogicamente, que desconstrua a hierarquização nas relações sociais. 
Um dos desafios para que as práticas interdisciplinares que considerem a interseccionalidade entre gênero, raça e classe sejam o cotidiano dos trabalhadores sociais, por exemplo, é a inserção precoce de alunos e alunas dos mais diversos cursos em diferentes cenários de ensino-aprendizagem, valorizando-se as relações no território e o contato mais direto com a problemática da violência nas famílias, movimentos e comunidades atendidas, bem como tendo o apoio social por meio das redes e as necessidades de saúde como categorias fundamentais para o cuidado integral em saúde.

Sendo assim, dependendo da concepção de educação que oriente o processo de ensinoaprendizagem e a produção de conhecimento (reprodutora ou transformadora), novas experiências entrariam em cena, colaborando para a construção coletiva de novos saberes e práticas socialmente mais responsáveis o que, em tempos de sucateamento das políticas públicas, de mercantilização da vida e de esgarçamento dos coletivos de ação, pode contribuir para o alargamento da consciência crítica dos sujeitos e, como decorrência, com seu engajamento em ações de transformação social (FREIRE, 1996). Identificamos aqui a potencialidade de apostarmos no diálogo fecundo entre os pressupostos feministas e freirianos para o acolhimento em saúde das mulheres em situação de violência.

\section{REFERÊNCIAS}

BERGER, Sônia Maria Dantas; BARBOSA, Regina Helena Simões; SOARES, Cecília Teixeira; BEZERRA, Cláudia de Magalhães. Formação de Agentes Comunitárias de Saúde para o enfrentamento da violência de gênero: contribuições da Educação Popular e da pedagogia feminista. Interface (Botucatu. Online). v.18, p.1241 - 1253, 2014.

BRASIL. Política Nacional de Redução da Morbimortalidade por Acidentes e Violências: Portaria MS/GM no 737 de 16/5/01, publicada no DOU no 96 seçãole, de 18/5/01 / Ministério da Saúde - Brasília: Ministério da Saúde, 2002.

BRASIL. Diário Oficial da União Lei $n^{0}$ 11.340, de 07 de agosto de 2006. Cria mecanismos para coibir a violência doméstica e familiar contra a mulher. Dispõe sobre a criação dos Juizados de Violência Doméstica e Familiar contra a Mulher; altera o Código de Processo Penal, o Código Penal e a Lei de Execução Penal; e dá outras providências. Diário Oficial da União, Poder Executivo, Brasília, DF, 8 ago, 2006. 
BRASIL. Presidência da República, Secretaria Especial de Políticas para as Mulheres. II Plano Nacional de Políticas para as Mulheres. Brasília, Secretaria Especial de Políticas para as Mulheres, 2008.

BRASIL. Ministério da Saúde. Secretaria de Atenção à Saúde. Departamento de Ações Programáticas Estratégicas. Linha de cuidado para a atenção integral à saúde de crianças, adolescentes e suas famílias em situação de violências: orientação para gestores e profissionais de saúde. Brasília: Ministério da Saúde, 2010

BRASIL. Secretaria de Políticas para as Mulheres - Presidência da República. Política Nacional de Enfrentamento à Violência Contra as Mulheres. Secretaria Nacional de Enfrentamento à Violência contra as Mulheres. Brasília, 2011

BRASIL. Portaria no 104, de 25 de janeiro de 2011. Define a relação dos agravos e evento de notificação compulsória em todo o território nacional e estabelece fluxo, critérios, responsabilidades e atribuições aos profissionais e serviços de saúde. Diário Oficial da União, Poder Executivo. Brasília: p.37-38, 2011 a.

BRASIL. Ministério da Saúde. Secretaria de Atenção à Saúde. Departamento de Ações Programáticas Estratégicas. Prevenção e tratamento dos agravos resultantes da violência sexual contra mulheres e adolescentes: norma técnica. $3^{\mathrm{a}}$ ed. Brasília: Ministério da Saúde; 2012.

BRASIL. Secretaria Especial de Políticas para as Mulheres. IV Conferência Nacional de Políticas para as Mulheres (CNPM). Documento-Base. Brasília, 2016.

CORRÊA, Sonia. Violência e os Direitos Humanos das Mulheres - A Ruptura dos Anos 90. Seminário Nacional Violência Contra a Mulher e as Ações Municipais das Mercocidades Brasileiras. Rio de Janeiro, Instituto Brasileiro de Administração Municipal, 7 e 8 de junho de 2001 ( mimeo).

DANTAS BERGER, Sônia Maria, GIFFIN, Karen. A Violência nas Relações de Conjugalidade: Invisibilidade e Banalização da Violência Sexual? Cadernos de Saúde Pública 21(2): 417-425, 2005.

DANTAS BERGER, Sônia Maria; GIFFIN Karen; SHIRAIWA Tizuko; AGUIAR, Janaína Marques. Pesquisa/Ação Como Ferramenta Estratégica em Serviços de Saúde: Uma Experiência Piloto na Formação Profissional para Acolhimento Qualificado da Violência Doméstica na Gravidez. IV Congresso Brasileiro de Ciências Sociais e Humanas em Saúde, Salvador, Bahia, Julho de 2007

DANTAS-BERGER, Sônia Maria; GIFFIN, Karen. Serviços de saúde e a violência na gravidez: perspectivas e práticas de profissionais e equipes de saúde em um hospital público no Rio de Janeiro. Interface - Comunic., Saúde, Educ. 2011, 15(37):391-405 
DANTAS-BERGER, Sônia Maria; CLARKSON, Elizabeth. Sobre a preceptoria como proposta de 'ensino ampliado': construindo um olhar integral da/na saúde sobre as violências. In: Cadernos do preceptor: história e trajetórias. Rio de Janeiro: CEPESC. IMS-UERJ. ISC- UFF. ABRASCO, p.151-170, 2014.

D’OLIVEIRA, Ana Flávia Pires Luca; SCHRAIBER, Lilia Blima. Políticas públicas e atenção às mulheres em situação de violência: contribuições acerca da integralidade em saúde. In: PINHEIRO, Roseni; ENGEL, Tatiana; ASENSI, Felipe Dutra (orgs). Vulnerabilidades e resistências na integralidade do cuidado: pluralidades multicêntricas de ações, pensamentos e a (re)forma do Conhecimento. Rio de Janeiro: CEPESC/IMS/UERJ, ABRASCO, 2017. P.91-103

FREIRE, Paulo. Pedagogia da autonomia: saberes necessários à prática educativa. São Paulo: Paz e Terra; $1996.165 p$

GIFFIN, Karen; DANTAS-BERGER, Sônia Maria. Violência de Gênero e Sociedade de Risco: Uma Abordagem Relacional. In: TAQUETTE, Stella R. (org). Violência Contra a Mulher Adolescente-Jovem. Rio De Janeiro: Eduerj; 2007. p 55-60.

GREGORI, Maria. Filomena. As Desventuras do Vitimismo. Revista Estudos Feministas, 1:143-149, 1993.

HARAWAY, Donna. Saberes localizados: a questão da ciência para o feminismo e o privilégio da perspectiva parcial. Cadernos Pagu (5), 7-41, 1995.

HECKERT, Ana. Redes de Políticas Públicas e os desafios para a Integralidade do Cuidado à Mulher: lugar de mulher é onde ela quiser. In: PINHEIRO, Roseni; ENGEL, Tatiana; ASENSI, Felipe Dutra (orgs). Vulnerabilidades e resistências na integralidade do cuidado: pluralidades multicêntricas de ações, pensamentos e a (re)forma do Conhecimento. Rio de Janeiro: CEPESC/IMS/UERJ, ABRASCO, 2017. P.104-116

HEISE, Lori; PITANGUY, Jacqueline \& GERMAIN, Adrienne. Violencia Contra la Mujer: La Carga Oculta sobre la Salud. Washington, D.C; Organización Panamericana de la Salud; 1994. 103 p. (OPS/PWD/94.006).

HEISE Lori, ELLSBERG Mary, GOTTEMOELLER Megan. Ending Violence Against Women. Population Reports, Series L, N 11. Baltimore, Johns Hopkins University School of Public Health, Population Information Program. Dezembro, 1999.

INSTITUTO PAPAI. Boletim "Outras Palavras" (Violência não é coisa de homem!) Instituto PAPAI- Capacitação, Pesquisa e Ação Política em Gênero e Saúde. Recife, fevereiro de 2003. 
INSTITUTO DE PESQUISAS ECONÔMICAS APLICADAS; FÓRUM BRASILEIRO DE SEGURANÇA PÚBLICA. Atlas da Violência 2018. Rio de Janeiro, junho de 2018. Disponível em http://www.ipea.gov.br/portal/index.php?option=com_content\&view=article\&id=33410\& Itemid=432. Acesso em 22 de julho de 2018.

KRUG, Ettiene; DAHLBERG, Linda; MERCY Anthony; LOZANO Rafael (Editors). World Report on violence and health. Geneva: World Health Organization, 2002

LIMA, Daniel Costa; BÜCHELE, Fátima; CLIMACO, Danilo de Assis. Homens, Gênero e Violência Contra a Mulher. Saúde Soc. São Paulo, v.17, n.2, p.69-81, 2008.

LUDERMIR, Ana Bernarda; SCHRAIBER, Lilia Blima; D’ÓLIVEIRA, Ana Flávia Pires Lucas; FRANÇA-JUNIOR, Ivan; JANSEN, Henrica. Violence against women by their intimate partner and common mental disorders. Social Science and Medicine 66(4), pp10081018, 2008.

MCFARLANE Judith; CAMPBELL Jacquelyn, SHARPS Phyllis. WATSON Kathy. Abuse During Pregnancy and Femicide: Urgent Implications for women's health. Am Coll Obstet Gynecol 2002; 100(1): 27-36, 2002.

MENDES, Corina Helena Figueira. Vozes do Silêncio: estudo etnográfico sobre violência conjugal e fertilidade feminina. Tese (Doutorado em Saúde da Mulher e da Criança) Instituto Fernandes Figueira, Rio de Janeiro, 2005.

MENEGHEL, Stela Nazareth; PORTELLA, Ana Paula. Feminicídios: conceitos, tipos e cenários. Ciência \& Saúde Coletiva, 22(9):3077-3086, 2017

MINAYO, Maria Cecília de Souza; SOUZA, Edinilsa Ramos de. É possível prevenir a violência? - reflexões a partir do campo da saúde pública. Ciência e Saúde Coletiva. 4 : 7 23, 1999.

NOLASCO, Sócrates. A Desconstrução do Masculino. Rocco: Rio de Janeiro, 1995

RAMSAY, Jean.; RIVAS, Carol.; FEDER, Gene. Interventions to reduce violence and promote the physical and psychosocial well-being of women who experience partner violence: a systematic review of controlled evaluations; Final Report, Center for Health Sciences, Barts and the London, London, 2005.

REICHENHEIM, Michael Eduardo [et al.]. Violência e lesões no Brasil: efeitos, avanços alcançados e desafios futuros. The Lancet. London, p.75-89, maio. 2011. Disponivel em: http://download.thelancet.com/flatcontentassets/pdfs/brazil/brazilpor5.pdf . Acesso em 14 de maio de 2018. 
SAFFIOTI, Heleieth. Contribuições Feministas para o estudo da violência de gênero. In: Labrys, Estudos Feministas. Revista número 1-2, julho/dezembro, 2001.

SCHRAIBER, Lilia Blima, D’OLIVEIRA, Ana Flávia Pires Lucas. Violência Contra a Mulher e Saúde no Brasil- Estudo Multipaíses da OMS sobre saúde da mulher e violência doméstica. [encarte principais resultados]. São Paulo: Faculdade de Medicina, Universidade de São Paulo, 2002.

SCHRAIBER, Lilia Blima, D’OLIVEIRA, Ana Flávia Pires Lucas, FALCÃO, Marcia Thereza Couto, FIGUEIREDO Wagner dos Santos. Violência dói e não é direito: a violência contra a mulher, a saúde e os direitos humanos. São Paulo: Editora UNESP, 2005

SCHRAIBER, Lilia Blima; D'OLIVEIRA, Ana Flávia Pires Lucas.; COUTO, Marcia. Thereza. Violência e saúde: estudos científicos recentes. Rev. Saúde Pública. São Paulo, v. 40, n. spe, Aug. 2006

SOARES, Gilberta Santos. Profissionais de saúde frente ao aborto legal no Brasil: desafios, conflitos e significados; Cadernos de Saúde Pública 19 (Sup2): S399-406, 2003

STEVENS, C.; OlIVEIRA, S.; ZANEllO, V.; SILVA, E.; PORTElA, C. (Orgs.). Mulheres e Violências: Interseccionalidades. 1. ed. Brasília: Technopolitik, 2017.

SUÁREZ, Mireya; BANDEIRA, Lourdes. Introdução a violência, gênero e crime no Distrito Federal. In: SUÁREZ, M. e BANDEIRA, L. (orgs.). Violência, Gênero e Crime no Distrito Federal. pp. 13-26, Brasília: Paralelo 15, Editora Unb, 1999.

VELZEBOER, Marijke; ELLSBERG, Mary; ARCAS, Carmen Clavel; GARCIA-MORENO, Cláudia. Violence Against Women: The Health Sector Responds. Washington, D. C.: PAHO (Occasional Publication $\mathrm{N}^{\mathrm{o}} 12$ )

VENTURINI, Gustavo; RECAMÁN; OLIVEIRA, Suely de. A mulher brasileira nos espaços público e privado. São Paulo: Editora Fundação Perseu Abramo, 2004.

VENTURINI, Gustavo; GODINHO, Tatau (Orgs.). Mulheres brasileiras e gênero nos espaços público e privado: uma década de mudanças na opinião pública. São Paulo: Fundação Perseu Abramo; Edições Sesc, 2013, 504p.

VILLELA W, MONTEIRO S. Atenção à saúde das mulheres: historicizando conceitos e práticas. Gênero e saúde: Programa Saúde da Família em questão. São Paulo: Arbeit; 2005. p. 15-31. 
WAISELFISZ, Júlio Jacob. Mapa da Violência 2015 - Homicídios de mulheres no Brasil. Brasília: Flacso Brasil, 2015. Disponível em: http://www.mapadaviolencia.org.br/pdf2015/ MapaViolencia_2015_mulheres.pdf. Acesso em 21 de julho de 2018

WHO. Department of Reproductive Health and Research, London School of Hygiene and Tropical Medicine, South African Medical Research Council. Global and regional estimates of violence against women: Prevalence and health eff ects of intimate partner violence and non-partner sexual violence. Geneva: World Health Organization, 2013.

Submetido em: $31 / 07 / 2018$

Aprovado em: 26/12/2018 